\title{
Einstein apaixonado: A ciência mal-contada de um mito bem-traçado
}

\author{
Carlos Alberto dos Santos
}

\author{
Universidade Federal do Rio Grande do Sul, Instituto de Física
}

O parágrafo de abertura de Einstein Apaixonado, livro recentemente publicado por Dennis Overbye, é um magnífico prenúncio de que o mito Albert Einstein será revelado em toda a sua complexidade psicológica. Overbye manipula bem as palavras e constrói frases bem acabadas. Senão vejamos: "Zurique, 1897. Albert Einstein, 18 anos, está sentado no seu quarto, deprimido e com pena de si mesmo. Seu corpo baixo e compacto está envolvido por um roupão esgarçado. (...) A luz de junho explode através das janelas que dão para a Unionstrasse, no coração do lendário e alastrado bairro estudantil. (...) O sol ri para todas as pessoas do mundo, menos para ele." A expectativa de ver a confirmação de um Einstein mitificado aumenta quando ainda no primeiro capítulo o autor se refere à cidade onde Einstein nasceu: "Ulm fica na Suábia, região de colinas ondulantes no extremo sudoeste da Alemanha (...) Para os alemães, a Suábia era uma espécie de Middle Earth ${ }^{1}$, um lugar tranqüilo habitado por camponeses amistosos e pequenos burgueses falando um dialeto pitoresco."

A maravilhosa construção do primeiro capítulo deixa o leitor sedento pela continuidade da leitura. Para quem conhece a literatura popular em torno de Einstein, sobretudo as biografias de Abraham Pais ${ }^{2}$ e Albrecht Fölsing ${ }^{3}$, nada é mais auspicioso. Depois de ver nessas biografias belas descrições do conhecimento científico desenvolvido por Einstein, é natural a expectativa por uma obra mitológica. Overbye mantém esta expectativa em bom ritmo até o início do quarto capítulo, quando ele se desvia do caminho sugerido e toma o rumo das biografias clássicas, com soluções perturbadoras. Na sua primeira investida (p. 64) ele discute "a nova teoria das ondas de luz de James Clerk Maxwell" e a controvérsia em torno da natureza da luz (corpuscular vs. ondulatória). Ao fazê-lo, não menciona a contribuição de Christian Huygens, um autor inesquecível no tratamento da teoria ondulatória. Para Overbye, o mérito pela defesa da teoria ondulatória cabe a René Descartes e Leonhard Euler. Outros equívocos factuais e privilégios históricos inapropriados acumulam-se ao longo do livro. Por exemplo, como é possível dizer que Maxwell "derivou quatro equações básicas, descrevendo o comportamento de campos e correntes, elétricos e magnéticos", sem sequer mencionar Gauss, Ampère e Faraday?

Mais adiante, na p. 111, Overbye diz que Lenard "descobrira que podia fazer com que os raios catódicos, Enviar correspondência para Carlos Alberto dos Santos.
www.if.ufrgs.br/einstein isto é, os elétrons, fossem emitidos de um metal expondo-o à luz ultravioleta". O leitor instruído em física percebe que o autor está se referindo ao efeito fotoelétrico, mas o principiante e o leigo terão dificuldade em descobrir isso, uma vez que Overbye não se refere ao fenômeno pela denominação que o popularizou. A confusão conceitual aumenta na p. 161, quando é dito que Lenard demonstrara "que não se pode fazer com que os elétrons saltem para fora de um metal expondo-o à luz ultravioleta". Na página seguinte Overbye decide usar o termo efeito fotoelétrico, e mais uma vez estabelece contexto histórico inapropriado: "Einstein propôs uma equação simples para o experimento de Lenard relacionando a freqüência da iluminação, as propriedades da placa de metal usada e a energia dos raios catódicos, pela qual sua explicação do `efeito fotoelétrico’ podia ser testada e verificada. Cerca de dez anos se passariam antes que Robert Milikan, um físico da Caltech, confirmasse aquelas previsões a caminho de um Prêmio Nobel". Ora, sabemos que o efeito fotoelétrico foi descoberto por Hertz. Lenard era seu assistente, e sob sua orientação realizou os experimentos sistemáticos mencionados por Overbye.

$\mathrm{O}$ autor perdeu a oportunidade de comentar o fato de que a equação do efeito fotoelétrico foi o principal motivo alegado pela Academia Real de Ciências da Suécia para conferir o Prêmio Nobel de 1921 a Albert Einstein. Esse lapso é mais notável ainda quando se percebe a referência feita ao Prêmio Nobel ganho por Milikan, no mesmo assunto. Uma pequena nota no final do livro (nota 18 do capítulo 24) informa que "Einstein ganhou o Prêmio Nobel do ano anterior pelo seu trabalho sobre o efeito fotoelétrico". Exemplos similares de conceitos mal explicados e desvios de contexto histórico são apresentados em várias partes do livro. A discussão em torno da radiação de corpo negro, absolutamente confusa, é mais um caso.

É provável que o leigo, não possuindo o conhecimento necessário para uma avaliação crítica, simplesmente considere a dificuldade de entendimento uma conseqüência da complexidade do assunto. Não é bem assim. Quando se trata da física, o texto é por vezes confuso por causa da apresentação inapropriada. Overbye escreve bem e poderia ter produzido uma obra memorável se permanecesse na esfera mitológica. Optou por seguir os passos dos biógrafos anteriores e não foi feliz na solução adotada para produzir um texto genuíno. Panoramas mais completos e digeríveis da obra de Einstein encontram-se em Abraham Pais e Albrecht Fölsing. Um fato que chama a atenção é que o livro de Fölsing mereceu apenas uma citação, no capítulo 3,

1 Terra Média: mundo de Fantasia criado por J.R.R. Tolkien em seu clássico O Senhor dos Anéis (Nota do tradutor, p. 21).

2 A. Pais, Sutil é o Senhor. A Ciência e a Vida de Albert Einstein (Nova Fronteira, Rio de Janeiro, 1995).

3 A. Fölsing, Albert Einstein (Peguin Books, Nova York:, 1997).

Copyright by the Sociedade Brasileira de Física. Printed in Brazil. 
p. 68. Comparando-se as duas obras, tem-se a impressão de que Fölsing inspirou Overbye em grande medida. Além disso, em vários aspectos relacionados com a discussão de conceitos físicos, o texto de Fölsing é bem mais claro que o de Overbye. Uma avaliação semelhante deve ter sido feita por Thomas Levenson. Em seu recente livro ${ }^{4}$ ele cita Fölsing 41 vezes, enquanto Overbye é citado apenas 3 vezes.

O livro apresenta os equívocos de tradução tão freqüentemente encontrados em textos científicos. Alguns casos são graves porque induzem o leigo a adotar terminologia equivocada. Em outros casos, pode resultar em informação errada, como na página 130, onde Max Talmey é apresentado como um "físico". No texto original deve constar physician, ao invés de physicist, uma vez que Talmey era aluno de medicina. Se o tradutor estivesse certo, o autor estaria errado.

Ao discutir a equação $\mathrm{E}=\mathrm{mc}^{2}$, Overbye diz (p. 186) que Einstein sugeriu "ser possível medir a massa perdida pelo rádio quando ele passava por degradação radiativa”.
Se Overbye não estava equivocado, ele deve ter escrito "radioactive decay", que significa "decaimento radioativo", nem "degradação", nem "radiativo".

Overbye fez correto uso dos 8 volumes da obra The Collected papers of Albert Einstein $5^{5}$. Na literatura inglesa isso passou a ser conhecido como The Collected papers project, ou The Einstein papers project. Não sei como está na versão original do livro, mas na edição brasileira foi adotada a expressão "Projeto Escritos de Einstein". Talvez a expressão Documentos Reunidos de Einstein seja mais apropriada.

Na p. 209, é usada a expressão "Sociedade Física Alemã". No original deve constar German Physical Society ou Deutsche Physikalische Gesellschaft. Qualquer que seja o caso, a melhor tradução é Sociedade Alemã de Física.

Em suma, Einstein Apaixonado nos brinda com maravilhosos trechos isolados, sobretudo aqueles nos quais vislumbramos o bem-traçado perfil de um mitológico Einstein. Por outro lado, o autor não conseguiu manter o mesmo nível de qualidade quando investiu nas discussões de conceitos físicos. 